\title{
Writing at the Centre: A Sketch of the Canadian History
}

Janet Giltrow

University of British Columbia

\section{Introduction}

This contribution to our national discussion on writing studies and writing centres takes the long view, seeing recent events-reorganisations, reclassifications-as a chapter in the history of writing centres in Canada. It is a long view, but neither as long nor as broad as it could be, for it is tethered to my own career in writing studies: this is what I have seen, from institutional positions I have occupied, and from scholarly positions I have taken. I hope others will extend this slender timeline with further episodes and comment, and with corrections, challenge, and inquiry. I offer some preliminary analyses of the forces and trends at work in the history-and future-of writing centres in Canada, hoping others with bring further and deeper analyses to the story.

\section{Writing Centres USA}

Although this brief history attempts a steady focus on the Canadian story, it cannot help but have in its peripheral vision the U.S. story. Like other aspects of the teaching of writing in Canada-some would say like the teaching of writing itself-the writing centre arrived here from America. The history of writing centres in Canada is illuminated or haunted, inspired or unnerved, by the U.S. story. From a distance, the Canadian story and the U.S. story might seem to run on parallel tracks. Emerging on the margins of institutions, writing centres, in Canada as in the U.S., strive for writing-centre activities to be recognised amongst the functions of core units. However, if we tune into some published views of the writing-centre field in the U.S., and draw a little closer to what the U.S. narrative says, we might want to reconsider the parallelism of the two tracks.

Evaluating competing origin stories for the U.S. writing center, Boquet (1999, p. 465) recognises the appeal and credibility of "counter-hegemonic" accounts, but finds greater 
Volume 26, 2016

http://journals.sfu.ca/cjsdw

explanatory power in Lerner's (1996; see also Lerner 2005, 2009) history of a genre emerging in the late $19^{\text {th }}$ century, namely, the 'writing conference': a meeting of student and teacher over an instance of the student's writing. Seemingly, the writing-and the need for the conference-has been produced by a required first-year composition course. On its way to becoming a stand-alone institutional unit, the writing conference evolved into the 'writing lab': conferences scheduled as part of the credit hours of a composition course. The conference then stepped free of the course schedule and occurred as the 'writing clinic', to which students were 'sent' for advice or correction, and eventually as the 'writing centre', at which students can still arrive for consultation by way of referral or on their own initiative.

Specialists would no doubt be able to tell a much more nuanced story of the evolution of the writing centre, but my non-specialist narrative would describe a trend towards the independence of the writing centre and a movement from the margins to the core, carrying students who were once said to 'need help' and now are said to 'struggle.' As writing-centre faculty or peer-tutors move towards the core, the focus of the work goes from grammar repair to consultation about an essay for a course (at first mainly a composition course but then any course) and most recently to the 'whole writer', envisaged 'beyond the curriculum.' The published record of this progress towards the whole student is propelled by many stories of redemption or realisation, for student or consultant or both, and by critical approaches to the structure of interaction in the writing centre. Concentrating on the features of interaction, the published record most recently engages affect and diversity, and proposes or reports strategies for training of tutors or faculty towards interactional ideals.

How are U.S. writing centres aligned institutionally and vis-à-vis the disciplines? Concerned with interactional models, and often occurring close to other 'academic support' units, the discussion from U.S. writing centres, in recent years at least, acknowledges but rarely attends to the voices of, as Bakhtin (1986) would say, the "spheres of activity" of the research disciplines. Yet the "idea of a writing center"-to draw on Stephen North's epic term (1984)-is not unmoored. Even recent contributions to the discussion presuppose or expect an affiliation with English, not only through writing studies programs but across broader shared domains of training in that field of the humanities. 
Volume 26, 2016

http://journals.sfu.ca/cjsdw

In this version of the narrative of U.S. writing centres, readers in Canada may find, in turn, areas of common ground or, instead, alien territory. Equally, they may recognise the view of writing centres from positions I will describe next, in a Canadian career in writing studies. Or these views may be less familiar than the picture from the U.S. scene.

\section{Writing Centres Canada: Simon Fraser University}

At Simon Fraser University, a mid-size, 'comprehensive' research institution in Burnaby, British Columbia, a municipality in the Metro Vancouver region, I first encountered the idea of the writing centre, in the late 1980 s and early 1990s. At that time, the clinic phrase could still prompt jokes about 'emergencies' and 'first-aid.' Oblivious then, I now remember no debate about the inauguration of clinic services. Was the writing clinic seen as a naturally occurring phenomenon? People may have had only a vague idea of the emergency and the treatment, beyond their own chronic fretfulness about students and writing. But people also seemed to have acknowledged, in a friendly if uninterested way, that this clinic would absorb excess. The main excess was that produced by undergraduate curriculum, especially in the humanities, where traditional pedagogies presumed rather than constructed understanding between professors and students as to the motives for writing. This gap produced a greater market for instruction than could be met by classroom teaching. Less likely to be acknowledged was another excess: an abundance of people with graduate degrees in the humanities, surplus to the job market. In ways which might be recognised from Bourdieu (1991), the excess demand produced by the curriculum shortfalls produced the market for the other surplus.

By the mid-1990s, like-minded colleagues at SFU-Michelle Valiquette prominent and fearless amongst them-felt we had erased the terms and images of 'clinic' and replaced them with scholarly commitment to inquiry into what our new upper-level course called "Writing and Response in the Research Genres." This course, as well as versions of it at the graduate level, not only trained consultants for the writing centre but also established core texts and concepts for our work, as well as research methodologies and a horizon of research questions. In other words, we disciplined the writing centre. By 1996 we were calling our project the Centre for Research in Academic Writing, leaving open and ready for innovation the matter of object of inquiry, agents of it, and means of dissemination of results. 
Volume 26, 2016

http://journals.sfu.ca/cjsdw

In daily practice, we were committed to the "think-aloud protocol," introduced to us by Schriver (1991) and Waern (1988), as the basis for interaction in the writing centre and, in addition, as a research tool. We were equally committed to rhetorical genre theory, coming to us from Miller (1984) and those who followed her lead, especially our colleagues at Carleton University in Ottawa (Aviva Freedman and the late, brilliant and beloved Peter Medway) and McGill University in Montréal (Anthony Paré and Graham Smart). We were committed to conceptualisations of language offered by Burke and Bakhtin, and by theorists who exposed the other face of language: the face of attitude. So we read and discussed the implications of Crowley (1989), Milroy and Milroy (1991[1985]), Cameron (1995), Bourdieu (1991) and others; we made our own contributions to study of ideologies of language, most notably Rea (2006). We knew from these readings and from our own observations that we were taking, in writingcentre policy and practice, positions which were not in accord with folk notions of language, or popular ideas about student writing. However, in the shelter of wellinformed administrative support for our work, we were protected not only from folk notions of language and correctness but also from strains of attitude issuing from the U.S. freshman-composition model of student writing.

We found further shelter in Richard M. Coe's distinguished scholarly presence in SFU's English Department. His reputation in rhetoric studies was a beachhead behind which we could land our small craft. Indeed, the Second International Genre Conference (1998), organised by Rick Coe, Lorelei Lingard, and Tatiana Teslenko, had as its proud junior partner the SFU writing centre. The visit of conference luminaries to CRAW may mark the furthest incursion of the writing centre into the hinterland of English Department respectability and opportunity. Changes were coming, and by the time of the Third International Genre Conference in Ottawa in 2012, the idea of a writing centreeven in its ambitious form, declaring for inquiry-had lost its top billing.

Strachan (2008) reports CRAW's extinction as prelude or condition for the "writingintensive" movement her book chronicles. Judiciously, Strachan tells how the English Department's leadership in academic-writing research and teaching entered a second phase as senior, university-level administrators began to consider options for extending and cultivating interest in writing in the disciplines-'writing in the research genres' having been thus at some point reconceptualised. The preferred option involved changes to curriculum and to degree requirements. This option put the project into the domain of 
Volume 26, 2016

http://journals.sfu.ca/cjsdw

central administration, and beyond the reach of the English Department. As the second phase of the English Department's leadership drew to a close, a third phase took shape. Under new administration, the Department disengaged from-even disavowed-the idea of a writing centre. As CRAW expired, the Centre for Writing-Intensive Learning (CWIL) arrived, hosted beyond the English Department.

Principles and practice developed in CRAW, however, survived in many forms. Some faculty members in CRAW were reassigned, and in their teaching and thinking continued in SFU English as active inquirers into the research genres. Other faculty members were not renewed, and moved to other institutions, as did those who graduated from undergraduate and graduate programs affiliated with CRAW. The career itineraries of these colleagues spread SFU-CRAW ideas across Canada: to the University of New Brunswick, St. John; Wilfrid Laurier University, Brantford; Brock University; Western University; Okanagan College, Vernon, BC, for example. Just beyond the Metro Vancouver region, the University of the Fraser Valley inherited CRAW principles and practices in their most generative form, as a dynamic package ready to develop productive new partnerships and, until last year, able to ward off damaging interventions. Elsewhere, two prominent CRAW members took founding leadership roles in the Arts Studies in Research and Writing unit at the University of British Columbia.

\section{Writing Centres Canada: University of British Columbia}

When in 1999 I arrived at the University of British Columbia, a 'medical-school' research institution in Vancouver, I saw, from a distance, a writing centre constructed on a model different from CRAW's. It had no research quarters in its architecture. And its connection to the neighbourhood English Department was different. Whereas the earliest 'clinic' phase at SFU may have nourished itself on the English-department flair for correction, CRAW connected to English through the department's recognition of rhetoric studies and through the Centre's position in the department's curriculum, both undergraduate and graduate. At UBC, beyond an informal sympathy the department might have felt for a unit devoted to correctness, there was a different and deep formal bond between English and the Writing Centre. This bond developed from the provision that, at UBC, students already admitted to the university were not automatically 
Volume 26, 2016

http://journals.sfu.ca/cjsdw

considered eligible for the (once numerous, now fewer) literature courses required for their degrees. If by other measures they did not show themselves ready for UBC English courses, they took a test called the Language Proficiency Index (LPI). Failing to achieve a satisfactory score on the LPI, students were (and are) strongly advised to go to the Writing Centre's fee-charging courses preparatory to further attempts at the LPI.

Changes in 2016 at the UBC Writing Centre were noticed and publicised by those engaged in writing studies in Canada, including members of Canadian Association for the Study of Discourse and Writing/Association Canadienne de Rédactologie (CASDW/ACR) and Canadian Writing Centres Association/Association Canadienne des Centres de Rédaction (CWCA/ACCR). It is not clear, however, that the first stage of change was as sharply consequential as many thought, or as disconcerting as others assumed. Everything that was in place before the intervention by the Provost's Office remains in place: the LPI courses; the courses brushing up people's 'grammar'; the help from tutors who talk to people about their writing. The Centre has relocated to the library's Learning Commons, and, inviting more people to consider themselves eligible for academic support, has renamed itself the Centre for Writing and Scholarly Communication.

From perspectives I developed during eight years in the Office of the Dean of Arts at UBC, the Learning Commons and now the Writing Centre appear like many entities of similar scale and profile occurring across the institutional landscape at the same time as that landscape become increasingly fertile to 'wellness' concerns. Lately, the wellness theme can sound also as 'student success.' Over the eight years I watched this landscape, resources flowed to such themes and related ones: stress, sexual assault, mental health, substance abuse, fitness, orientation, for example, and the negative externalities of another import from the U.S., Frosh Week. The biggest roles in managing those resources were taken by staff rather than faculty. As the whole panorama of 'campus life' came into view, it was found that there were many facets of it to be managed, and many of those could be captured under the notion of transition-students' transition from secondary school to post-secondary. Transition has been a theme, too, for writing centres. Writing centres volunteer to help students scale that steep curve from writing for high-school classes to writing for university courses.

Prominent, professionally affiliated, and numerous, staff were on hand to help with or even to organise and direct many of the institution's activities. Early in my years in the 
Volume 26, 2016

http://journals.sfu.ca/cjsdw

Dean's Office, I found, for example, that staff expertise had finally turned an often-naïve admissions process into sophisticated 'enrolment management.' And Faculties could now leave staff in the driver's seat; in fact, they had to do so, for senior staff were the only ones who knew where the keys were. A few more years into my term in the Dean's Office, I was encouraged and coached by admissions staff to develop Broad-Based Admissions for Arts. Accordingly, a committee of faculty members designed instruments and processes to assess applicants' intellectual readiness (rather than merely rank their GPA), and implemented both, to the satisfaction of many. Students wrote in response to prompts, and faculty members read the writing. Within three years, however, our homemade, faculty-designed instrument had been taken over by staff: standardised across Faculties, directed away from intellectual readiness and towards whole-person fitness, the admissions process now sends the writings of applicants only to staff, and no longer to faculty. So, when writing-centre functions drift towards readers who are designated as staff, I see them as carried by broader currents flowing across the university. It is tempting, I am sure, to call this corporatisation, and there may be justice to such an analysis-but there may also be a more complicated story to discover.

One might follow, for example, how some terms found in the U.S. discussion of writing centres are tributary to the student-success current. So, in a recent review of writing centre positioning in U.S. institutions, Salem (2015) is suspicious of the kind of institutional blends - writing centres merging with other academic support - which Lunsford and Ede (2011), in an oracular celebration of writing-centre philosophy and practice, earlier warned against. Yet, in looking for writing's unmerged separateness, Salem also comes across an alliance: "the hallmarks of writing center pedagogy align almost perfectly with the liberal arts educational narrative" of "personal transformation" (p. 35). For even as writing-centre practice helps students with course assignments, it goes beyond curriculum, to "privilege individual students' individual development" ( $p$. 35). Salem hears a U.S.-accented liberal-arts narrative; the tale is different in Canada. But there may be a route linking these two stories which transcend curriculum, through what Arts studies in Canada routinely claims: graduates with 'critical-thinking and communication skills'-no matter the discipline. Echoing that claim, writing centres, even in Canada, can offer to help with organisation, thinking, the writing process-no matter the discipline. 
Volume 26, 2016

http://journals.sfu.ca/cjsdw

\section{Writing Centre Futures}

Why are writing centres more vulnerable to intervention and interruption than other academic units? Although we hear sometimes about disciplinary coalitions with a fresh mandate or about traditional disciplines being reduced or re-accommodated, we would be surprised indeed to hear of traditional disciplines being reclassified and relocated. We would be surprised to hear of, say, Classics being asked to share institutional space with admissions or orientation.

We may be alarmed but we are not surprised to hear of organisational interference in writing centres in Canada-or elsewhere. Lunsford and Ede (2011) recapitulate the "peripatetic" career of the writing centre depicted by Nancy Grimm (1999), not for its being unusual but for its six or seven institutional locations and re-locations over a few years being typical of U.S. writing-centre histories. In their study of career paths for U.S. 'Writing Center Professionals', Geller and Denny (2013) find a nearly bewildering array of types of appointments for writing centre professionals, and, accordingly, types of reorganisation and reclassification to which writing centres are subject. Unlike instruction in other disciplines, the teaching of writing is itself radically exposed to organizational forces of budget allocations and staff realignments - 'radically' insofar as it can be up-rooted much more readily than can instruction in other disciplines. Why is it so vulnerable?

In some ways, writing studies and writing centres have cooperated in their own exposure by accepting, you might say, campaign donations from unreliable sources. Among the most treacherous of these are the literacy alarmists and language purists; the advocates of grammar instruction with a hint of literary appreciation. Another source of support, more respectable and less fanatic but still undependable, are the colleagues who, perennially, want to see student writing 'improved'; the programs and departments which want what they call communication skills for their curriculum and imagine 'writing assistance' for their students. Both sources of support can compromise the project from the very start, by speaking for writing studies, and drawing on folk assumptions (students today can't write; employers want communication skills; etc.). Possibly flattered by the attention, writing studies lets these supporters make the case for teaching writing and establishing writing centres. Seems too good to be true! And it is. This support is unsecured. Overnight, it can drift to another cause: a network of peer 
Volume 26, 2016

http://journals.sfu.ca/cjsdw

helpers, a website on punctuation or plagiarism, an affiliation with a consortium of internet-based resources, or some other campaign. Or the excitement can die down to nothing, to a period of dormancy, only to be revived later (we used to have a communications-skills course, we'd better get it back!).

Is the answer then to make the case, in the discipline's own terms? Unfortunately, this is not exactly the answer, for even as we accept donations from these sources, we know they have no grasp-worse, they want no grasp-of the research-attested bases of the teaching of writing, whether that research be theoretical/conceptual, rhetorical, longitudinal, discourse-analytic, historical, qualitative, corpus-based, or other. We know that the disciplined case is incompatible with notions of language entertained by supporters, whether the fanatical or more moderate ones. So, when Writing Studies depends on these supporters, it ends up claiming too little for itself, as others speak on its behalf. And it's left exposed and vulnerable.

Writing studies and writing centres may also claim too much for themselves, and in this way also make themselves vulnerable as a discipline.

Writing studies is alone amongst the disciplines in offering itself as a service to all students all the time - alone except for Math. Math could be distinguished company, but it keeps to itself, while 'writing' consorts with 'studying,' and 'managing time'. These are undisciplined activities, as are others advertised by writing centres: writing a thesis statement, structuring paragraphs, communicating ideas to professors, even 'thinking.' These services claim too much - all thinking, all students, all the time. So claiming, writing de-disciplines itself, territorializing a wide area which, nowadays, it has to share with student services: the growing non-academic sector of the university described above-wellness, retention, transition, clubs, leadership, travel, development, counselling-and devoted to producing the student experience rather than the scholarly experience. These forces are bound to overtake the thesis statement and paragraph structure - bit players (tiny bit) in the student-success story. Sorted with the studentsuccess model, the writing centre ends up recruited to its own de-disciplining and devaluation. And by claiming too much, it may seem to volunteer for this model.

Student success may be a new and particularly aggressive or fit competitor for resources, but the problem of claiming too much is longstanding. If there is going to be just one course that is required of first-year students, chances are good (but not certain, of course) that it will be a writing course. Who would we be to object? Good news! 
Volume 26, 2016

http://journals.sfu.ca/cjsdw

Another flattering moment. But, historically, there may have been a high cost to being the only discipline to claim this wide applicability. Under this dispensation, practicalities alone will isolate writing studies. How do you staff the requirement or the service? Is it going to be a problem of qualifications-where to find all the tenurable candidates? Could any discipline enter this market, without distortions? Or will it be a problem of cost? Everyone takes the course, in small classes, or visits a writing centre for one-onone instruction. To keep costs down, positions are classified in a special way. They are taken off the rails of the tenure track, which cannot deliver such large numbers of faculty positions; they are de-railed, and de-disciplined.

An expanding writing centre, like a required course, is good news for a while-but there is a cost to writing studies as a discipline.

\section{Navigating the Hazards}

How can Canadian writing centres position themselves to resist forces that lead them to claim too much - or too little? Can they protect themselves from up-rooting and dislocation, from redefined status or compromised mission?

Other academic units are defined and deep rooted through their disciplines: research methodologies, traditions of inquiry and reputations for expert accountability. In other words, they are recognised for how they make knowledge. What can be said of the knowledge-making of writing centres?

The matter awaits closer inspection from people more familiar than I with current projects in writing centres in Canada. In the meantime, I will sketch one view, from a distant perspective. Sweeping rather than penetrating, and brief rather than properly prolonged, the view is taken through the lens of genre: around which genres is knowledge accruing, or applying? Through this lens I can see, as reported above, in the U.S. a growing concentration on the genre of the interaction between student and writing-centre consultant. The growing concentration appears to coincide with announced interest in the 'whole' writer-and with U.S. writing centres' trending towards recognition as a core activity. From here, it looks as if writing centres are finding their place under the auspices of a compatible national educational culture. In postsecondary America, the consultation genre is at home historically, tracing its genealogy 
Volume 26, 2016

http://journals.sfu.ca/cjsdw

to the writing conference and the traditions of freshman composition, and coordinating its message with the liberal-arts' values of personal transformation.

Such themes may be heard in post-secondary Canada too, but they are not configured for the same dominance. Canadian writing centres would be taking a risk to focus similarly on the genre of the student/consultant interaction. In Canada, absent the historical imagery of personal transformation, the stronger pull is towards the 'student experience', managed by the office of 'student success', where writing would share desk space with transition and retention.

In both Canadian and American writing-centre scenes, the genre lens can also pick out the student essay. Coming from the family of classroom genres-others including discussion, quiz, mid-term, final exam-the student essay presents for attention in the writing centre. With the teacher as its only user, the essay genre is unknown outside schooling. Scholars do not take up a topic after brief consideration, and write $8-10$ pages or even 18 - 20 pages while composing several other documents of equal length at the same time, to be delivered to their sole readers within a few days of one another. (And this quick caricature, of course, only begins to expose the gap between the studentessay genre and the genres of working scholarship.)

Woven into the screen of classroom genres, student writing is curtained-off from the practical activity of scholarly discourse. And writing centres can get trapped behind that partition, too, sometimes by the very terms they use to express knowledge of the studentessay genre. One doesn't have to look far to find these terms on display: brainstorming, idea-focussing, outlining, 'researching,' drafting, revising, revising for 'grammar', and so on. What kind of knowledge is this? We could say, at best, that these terms are off-theshelf: widely available for decades if not generations. We could not say that this knowledge is expert or specialist, for the claims that issue from these terms are neither methodologically disciplined nor tested or held accountable by research communities. When this is the knowledge which appears to be on offer, in institutions which accumulate assets in the hard currency of international reputation in the research disciplines, it's not hard to see how these offerings are unlikely to enjoy the same security as those advanced by other academic units. Where small markets for 'essay help' do prosper, they may owe their survival to the comfort of the commonplaces. At the same time, such commonplaces can be treacherous, for, having no scholarly provenance, they are easily deliverable from a staff position. 
Volume 26, 2016

http://journals.sfu.ca/cjsdw

Although I gathered the snippets above, about outlining and drafting, from writingcentre websites in Canada, they doubtless do not stand for the broad character of knowledge housed in, produced by, and used in writing centres in Canada. Yet even if we do find that the student-essay is generally regarded sceptically rather than naively, we still have to say that, nevertheless, all writing centres are to some extent caught behind the screen of classroom genres, separated from the genre networks of research cultures. This a feature of the writing-centre predicament, as are the shelves overstocked with commonplaces about student writing.

What should or could the genre focus be? How might a horizon of discourse studies be established for Canadian writing centres? If I were a writing centre administrator, I would go carefully to avoid the hazards of the writing-centre predicament. I would avoid idealising the genre of the student/consultant interaction. I would keep track of what the writing centre says about student genres: seemingly harmless commonplaces about thesis statements and outlines could cost the writing centre in the long run. I would invest instead in study of those genres, so that the findings would qualify writing-centre faculty as specialists in curricular reform and in significant rather than only technical innovation. I would steer towards the genres and meta-genres (Giltrow 2002) of the research disciplines and the study of disciplinarity itself, to cultivate historical and sociopolitical knowledge of the disciplines and their ways of incorporating new generations into the body of knowledge. I would decline invitations to participate in sessions on tipsfor-writing, whether face-to-face or mediated.

All this said, I know still that even careful navigation might not ensure the safe passage of the writing centre.

\section{Acknowledgements}

To colleagues from the Centre for Research in Academic Writing at Simon Fraser University, I owe a great debt. In addition to those already named above, I salute the following friends and fellow scholars: Kathryn Alexander, Daniel Dunford, Fay Hyndman, Sharon Josephson, Dana Landry, Shurli Makmillen, Kim Norman, Katharine Patterson, Marlene Sawatsky, Nadeane Trowse, Anneke Van Enk, Bonnie Waterstone, Diana Wegner. 
Volume 26, 2016

http://journals.sfu.ca/cjsdw

\section{References}

Bakhtin, M. M. (1986). The problem of speech genres. In C. Emerson and M. Holquist (Eds.), (V. W. McGee, Trans.), Speech genres and other late essays. Austin, TX: University of Texas Press.

Boquet, E. (1999). 'Our little secret': a history of writing centers pre- and post-open admissions. College Composition and Communication, 5O(3), 463-482.

Bourdieu, P. (1991). The production and reproduction of legitimate language. In J. B. Thompson (ed.), (G. Raymond \& M. Adamson, Trans.), Language and symbolic power. Cambridge, MA: Harvard University Press.

Cameron, D. (1995). Verbal hygiene: the politics of language. London and New York: Routledge.

Crowley, T. (1989). Standard English and the politics of language. Chicago and Urbana, IL: University of Illinois Press.

Geller, E. A., \& Denny, H. (2013). Of ladybugs, low status, and loving the job: Writing Center Professionals navigating their careers. Writing Center Journal, 13(1), 96-129.

Giltrow, J. (2002). Meta-genre. In Coe, R. Lingard, L. \& T. Teslenko (Eds.), The Rhetoric and Ideology of Genre, 187-206. Cresskill, NJ: Hampton Press.

Grimm, N. (1999). Good intentions: writing center work for postmodern times Portsmouth, NH: Boynton Cook.

Lerner, N. (1996, March). The writing conference as dominant practice: an historical view. 12 ${ }^{\text {th }}$ Annual New England Writing Centers Association Conference. Amherst, MA.

Lerner, N. (2005). The teacher-student writing conference and the desire for intimacy. College English, 68(2), 186-208.

Lerner, N. (2009) The idea of a writing laboratory. Carbondale, IL: Southern Illinois University Press.

Lunsford, A. A., \& Ede, L. (2011). Reflections on contemporary currents in writing center work. Writing Center Journal, 31(1), 11-24.

Milroy, J., \& Milroy, L. (1985/1991). Authority in language: investigating language prescription and standardisation. New York, NY: Routledge.

North, S. (1984). The idea of a writing center. College English, 46(5), 433-446. 
Rea, J. (2006). Ideologies of language: Authority, consensus and common sense in Canadian talk about usage (Doctoral dissertation). Retrieved from http://summit.sfu.ca/

Salem, L. (2015). Opportunity and transformation: how writing centers are positioned in the political landscape of higher education in the United States. Writing Center Journal, 34(1), 15-43.

Schriver, K. A. (1992). Teaching writers to anticipate readers' needs: a classroom pedagogy. Written Communication, 9(2), 179-208.

Strachan, W. (2008). Writing-intensive: Becoming W-faculty in a new writing curriculum. Logan, UT: Utah State University Press

Waern, Y. (1988). Thoughts on text in context: applying the think-aloud method to text processing. Text, 8(4), 327-350. 